\title{
Oxidative stress during acute respiratory exacerbations in cystic fibrosis
}

\author{
L T McGrath, P Mallon, L Dowey, B Silke, E McClean, M McDonnell, A Devine, \\ S Copeland, S Elborn
}

\begin{abstract}
Background-Patients with cystic fibrosis experience chronic systemic oxidative stress. This is coupled with chronic inflammation of the lung involving bronchial polymorphonuclear neutrophil accumulation and activation. We hypothesised that, during periods of acute respiratory exacerbation, free radical activity and consequent damage would be most marked and that intensive treatment of the infection would result in improvement towards values found during stable periods.

Methods-Plasma and red blood cells were collected from 12 healthy normal volunteers and from 12 patients with cystic fibrosis with an acute respiratory exacerbation (increased respiratory symptoms, reduction in forced expiratory volume in one second $\left(\mathrm{FEV}_{1}\right)$ of more than $10 \%$, and a decision to treat with intravenous antibiotics). Further samples were collected from patients following two weeks of treatment. Samples were analysed for inflammatory markers, markers of free radical damage, and aqueous and lipid phase scavengers.
\end{abstract}

Results-During respiratory exacerbations $\mathrm{FEV}_{1}$ and forced vital capacity (FVC) were lower than in controls (mean differences $-2.82(95 \%$ CI -2.12 to -3.52$)$ and -3.79 ( -3.03 to -4.55$) 1$, respectively) but improved following treatment (mean change $0.29(95 \% \mathrm{CI} 0.18$ to 0.40$)$ and 0.33 $(0.23$ to 0.43$) 1$, respectively). Inflammatory markers during exacerbations were significantly higher in patients than in controls with the following mean $(95 \% \mathrm{CI})$ differences: $C$ reactive protein (CRP), 46 (17 to 75$) \mathrm{g} / 1$; neutrophil elastase $\alpha_{1}-$ antiprotease complexes (NEAPC), 4.4 (1.77 to 7.07$) \mathrm{mg} / \mathrm{l}$; white cell count (WCC), $5.3(4.7$ to 5.9$) \times 10^{9} / 1$. These markers decreased significantly following treatment with the following mean $(95 \%$ CI) changes: CRP $-26(-10$ to -42$) \mathrm{g} / \mathbf{1}$; NEAPC $-3.1(-1.3$ to -4.9$) \mathrm{mg} / 1$; WCC -1.5 $(-1.3$ to -1.7$) \times 10^{9} / 1$. Malondialdehyde (MDA) as a marker of free radical activity was significantly higher in patients during exacerbations than in controls with a mean (95\% CI) difference of 193 (107 to 279) which improved with treatment (mean change $-56 \quad(95 \%$ CI -28 to -84) $\mathrm{nmol} / \mathrm{mmol}$ cholesterol). Red blood cell polyunsaturated fatty acids were significantly lower in patients than in controls with a mean difference of $-4.4(95 \%$
CI -2.6 to -6.2 ) moles percent, but did not improve significantly after treatment. Protein carbonyls during exacerbations were not different from controls but did increase with treatment compared with levels during the exacerbation (mean change 0.39 (95\% CI 0.11 to 0.67$) \mu \mathrm{mol} / \mathrm{g}$ protein). Aqueous and lipid phase scavengers in patients during exacerbations were significantly lower than in controls with the following mean (95\% CI) differences: ascorbate, $-19.0 \quad(-2.7$ to -35.3$) \mu \mathrm{mol} / 1$; sulphydryls, $-122(-77$ to -167$) \mu \mathrm{mol} / 1$; retinol, $-237 \quad(-47$ to -427$) \mathrm{nmol} / \mathrm{mmol}$ cholesterol; $\beta$-carotene, $-52.8 \quad(-11.8$ to -93.8) $\mathrm{nmol} / \mathrm{mmol}$ cholesterol; luteine, $-50.4(-10.4$ to -90.4$) \mathrm{nmol} / \mathrm{mmol}$ cholesterol; lycopene, $\mathbf{- 9 0 . 1}(-30.1$ to $-150.1) \mathrm{nmol} / \mathrm{mmol}$ cholesterol. Treatment resulted in improvement with the following mean (95\% CI) changes: sulphydryls, 50 (32 to 68) $\mu \mathrm{mol} / 1$; retinol, 152 (47 to 257$) \mathrm{nmol} / \mathrm{mmol}$ cholesterol; $\alpha$ - and $\beta$-carotene, $0.6(0.0$ to 1.2$)$ and $7.6(0.0$ to 15.2) $\mathrm{nmol} / \mathrm{mmol}$ cholesterol, respectively; $\alpha$-tocopherol, $839 \quad(283 \quad$ to 1405) $\mathrm{nmol} / \mathrm{mmol}$ cholesterol; and lycopene, $8.2(0.0$ to 16.2$) \mathrm{nmol} / \mathrm{mmol}$ cholesterol.

Conclusions-Abnormalities of markers of inflammation, free radical activity, and radical scavengers were significantly more extreme during acute respiratory exacerbations and showed improvement with treatment. The need to provide protection from inflammation and free radical damage should therefore be dynamic and related to the inflammatory and oxidative processes.

(Thorax 1999;54:518-523)

Keywords: cystic fibrosis; oxidative stress; respiratory exacerbation

The involvement of pro-oxidant free radicals in the pathogenesis of a number of diseases such as atherosclerosis, cancer, and post-ischaemic reperfusion induced injury is now well established. ${ }^{1-3}$ While not definitive, evidence is now accumulating for a role for free radicals in cystic fibrosis. ${ }^{4}$ Chronic inflammation involving bronchial polymorphonuclear neutrophil accumulation is characteristic of the airways disease associated with cystic fibrosis. A consequence of this persistent inflammation and repeated cycles of infection is progressive lung damage and pulmonary fibrosis which are 
responsible for over $90 \%$ of the observed mortality. ${ }^{5}$

Although the genetic defect responsible for cystic fibrosis is well described, the exact mechanism of this damage remains unclear. Repeated infections result in an increased immune response with a 1000 fold increase in the numbers of neutrophils recovered from the lungs of patients with cystic fibrosis. ${ }^{6}$ While free radical generation by these activated neutrophils is important in the killing of the pathogens, they may damage pulmonary epithelium. ${ }^{7}$ This problem is exacerbated by a deficiency in systemic antioxidant activity, in part due to malabsorption of fat soluble antioxidants secondary to pancreatic insufficiency and in part due to increased consumption of these scavenger molecules. In addition to this imbalance in the oxidant/antioxidant system in favour of oxidative damage, there is evidence that patients with cystic fibrosis may also experience increased intracellular free radical generation. This is secondary to leakage of electrons from increased electron transport system activity in the mitochondria which act as a source of partially reduced oxygen intermediates. ${ }^{8}$ Thus, there may be two mechanisms driving free radical chemistry in patients with cystic fibrosis coupled with impaired antioxidant systems.

The purpose of the present study was to examine the hypothesis that patients with cystic fibrosis are subjected to acute free radical stress during acute respiratory infection which is additional to the chronic systemic free radical attack found in this condition. We examined patients recruited during a symptomatic exacerbation of their lung disease, then again after two weeks of intense antibiotic treatment.

\section{Methods}

SUBJECTS

Twelve patients with cystic fibrosis (eight men) and 12 healthy controls (nine men) were studied. Patients with cystic fibrosis had a prior diagnosis by genotype and/or sweat testing (sweat sodium concentration $>70 \mathrm{mmol} / \mathrm{l}$ ) and in vitro cultures of sputum showing chronic colonisation by one or more organisms associated with cystic fibrosis. All patients were receiving vitamin $\mathrm{E}$ supplementation $(200 \mathrm{mg}$ per day). The patients were recruited at a time of symptomatic exacerbation of their lung disease defined as a reduction in forced expiratory volume in one second $\left(\mathrm{FEV}_{1}\right)$ of more than $10 \%$ compared with the best in the previous year, an increase in respiratory symptoms, and a decision to treat with intravenous antibiotics. Samples were collected at the time of admission to hospital before commencement of treatment and again following two weeks of antibiotic treatment. Control subjects had no personal or immediate family history of cystic fibrosis and no evidence of illness at the start of or during the trial. Controls were excluded if they were on any antimicrobial medication at the start of or at any time during the trial. The study was approved by the local ethics committee and informed consent was obtained from all participants prior to initiation of the protocol.

SAMPLE COLLECTION AND TREATMENT

The sampling protocol was designed to minimise oxidation after collection. $20 \mathrm{ml}$ of venous blood was collected from subjects and divided between a heparinised tube and a tube containing EDTA. Samples were gently mixed, packed in ice, and prepared immediately. All samples were maintained at $4^{\circ} \mathrm{C}$ throughout preparation. $1.0 \mathrm{ml}$ EDTA blood was set aside for preparation of red blood cell membranes. Erythrocytes were washed four times with 10 volumes of ice cold isotonic sodium phosphate buffer $(0.15 \mathrm{~mol} / \mathrm{l}, \mathrm{pH}$ 7.40, $310 \mathrm{mOsm}$ containing $3.4 \mathrm{mmol} / \mathrm{l}$ EDTA) and the buffy coat removed. The washed erythrocytes were lysed, centrifuged at $20000 \mathrm{~g}$, and the packed membranes were stored for analysis of fatty acid composition as haemoglobin free ghosts at $-80^{\circ} \mathrm{C}$ in albumin $(2.5 \mathrm{~g} / \mathrm{l})$ and $3.4 \mathrm{mmol} / 1$ EDTA containing phosphate buffer $(0.15 \mathrm{~mol} /$ $1, \mathrm{pH}$ 7.40). The remaining heparinised and EDTA containing blood was centrifuged at $3000 \mathrm{~g}$ for 10 minutes at $4^{\circ} \mathrm{C}$. $500 \mu \mathrm{l} \mathrm{EDTA}$ containing plasma was mixed with $500 \mu 110 \%$ $(\mathrm{w} / \mathrm{v})$ aqueous metaphosphoric acid and centrifuged at $3000 \mathrm{~g}$ for five minutes at $4^{\circ} \mathrm{C}$. The supernatant was removed and set aside for analysis of ascorbate. Heparinised plasma was divided into aliquots and set aside for analysis of selenium, copper, zinc, ubiquinol 10, carotenoids, reduced protein thiols, and protein carbonyls. $500 \mu \mathrm{l}$ of the plasma for analysis of carbonyls was mixed with $50 \mu 10.2 \%$ (w/v) ethanolic butylated hydroxy toluene (BHT) as antioxidant. Plasma containing EDTA was aliquoted and set aside for analysis of malondialdehyde (MDA) and vitamin E. $500 \mu \mathrm{l}$ of the plasma for analysis of MDA was mixed with $50 \mu 10.2 \%$ (w/v) ethanolic BHT. All of these samples were stored at $-80^{\circ} \mathrm{C}$ and analysed within four weeks.

PULMONARY FUNCTION TESTS

Measurements taken included $\mathrm{FEV}_{1}$ and forced vital capacity (FVC) using a vitalograph spirometer. These procedures were repeated in patients at the end of the two week treatment period.

CRP AND NEUTROPHIL ELASTASE $\alpha_{1}$-ANTIPROTEASE COMPLEXES

$\mathrm{C}$ reactive protein (CRP) was measured by rate nephelometry using a Beckman analyser and neutrophil elastase $\alpha_{1}$-antiprotease complexes (NEAPC) were measured using an ELISA. ${ }^{9}$

\section{BIOCHEMICAL ANALYSES}

MDA was determined by high performance liquid chromatography (HPLC) and total cholesterol was measured enzymatically as previously described. ${ }^{10}$ Total plasma sulphydryls and protein carbonyls were assayed spectrophotometrically. ${ }^{11}{ }^{12}$ Protein carbonyl results were expressed per g protein. Carotenoids, which included $\alpha$ - and $\gamma$-tocopherol, $\alpha$ and $\beta$-carotene, retinol, lycopene and luteine, were assayed simultaneously by an HPLC 
Table 1 Mean (SE) values for pulmonary function tests and inflammatory markers in patients with cystic fibrosis during an exacerbation and after antibiotic treatment and in controls

\begin{tabular}{llll}
\hline & \multicolumn{2}{l}{ Patients $(n=12)$} & \\
\cline { 2 - 3 } & Exacerbation & After treatment & Controls $(n=12)$ \\
\hline FEV $_{1}(1)$ & $1.6(0.3)^{\mathrm{a} 1}$ & $1.89(0.3)^{\mathrm{a} 1 \mathrm{a}, \mathrm{a} 2}$ & $4.42(0.3)$ \\
$\mathrm{FVC}(1)$ & $2.37(0.35)^{\mathrm{a} 1}$ & $2.70(0.40)^{\mathrm{a} 1 \mathrm{a} 2}$ & $5.16(0.30)$ \\
$\mathrm{CRP}(\mathrm{g} / \mathrm{l})$ & $48(19)^{\mathrm{a} 1}$ & $22(7)^{\mathrm{a} 1 \mathrm{a}, \mathrm{a} 2}$ & $2(0.6)$ \\
$\mathrm{NEAPC}(\mathrm{mg} / \mathrm{l})$ & $4.6(2.4)^{\mathrm{a} 1}$ & $1.5(0.6)^{\mathrm{a} 1 \mathrm{a} 2}$ & $0.18(0.02)$ \\
WCC $\left(\times 10^{9} / 1\right)$ & $10.8(0.8)^{\mathrm{a} 1}$ & $9.3(0.7)^{\mathrm{a} 1, \mathrm{a} 2}$ & $5.5(0.2)$ \\
\hline
\end{tabular}

$\mathrm{FEV}_{1}=$ forced expiratory volume in one second $\mathrm{FVC}=$ forced vital capacity; CRP $=\mathrm{C}$ reactive protein; NEAPC $=$ neutrophil elastase $\alpha_{1}$-antiprotease complexes; WCC $=$ white cell count. ${ }^{\mathrm{a}} \mathrm{p}<0.05,{ }^{1}$ versus control, ${ }^{2}$ versus value during exacerbation.

method described by Thurnham et al..$^{13}$ Ascorbate and ubiquinol 10 were measured by HPLC as described by Inyama et al and Stocker et al, respectively. ${ }^{14}{ }^{15}$ The results of analyses of all fat soluble vitamins, scavengers, and MDA were lipid standardised and expressed per mole of total cholesterol. Lipid was extracted from red blood cell membranes, saponified, derivatised with pentafluorobenzene and analysed by capillary gas chromatography with electron capture detection as previously described. ${ }^{16}$ The percentage of the total fatty acids comprised of polyunsaturated fatty acids (PUFAs) was calculated from the individual fatty acids. This was expressed as moles percent.

ANALYSIS OF DATA

Data were analysed using the SPSS package (SPSS Inc, Chicago, Illinois, USA). Comparisons between the two groups (patients during exacerbation and controls) were made using the Mann-Whitney rank sum test and comparisons between patients before and after treatment were made using Wilcoxon's matched pairs signed ranks test. Absolute values are summarised in tables 1-3 and expressed as means (SE). The mean differences between patients and controls and mean changes within the patient group following treatment are given with $95 \%$ confidence intervals for the difference/change. A p value of 0.05 or less was considered significant.

\section{Results}

SUBJECTS

The average age of the patients was 25 years (range 22.4-27.7) and of the controls was 24.9 years (range 23.8-26.0). Of the patients, seven (58\%) were chronically colonised by Burkholderia cepacia while five (42\%) were chronically colonised with Pseudomonas aeruginosa.

CLINICAL AND INFLAMMATORY MARKERS

Absolute mean (SE) levels of the clinical and inflammatory markers in patients and controls are summarised in table 1 . During acute respiratory exacerbations the patients had a significantly lower $\mathrm{FEV}_{1}(1.6$ (0.3) 1) than the controls $(4.42(0.3))$, mean difference -2.82 (95\% CI 2.12 to 3.52$) 1(\mathrm{p}<0.05)$. Similarly, FVC was lower in the patients than in the controls $(2.37(0.35)$ versus $5.16(0.30))$, mean difference -3.79 (95\% CI 3.03 to 4.55$) 1$ $(p<0.05)$. Both $\mathrm{FEV}_{1}$ and FVC increased significantly in the patients following treatment
$\left(\mathrm{FEV}_{1} 1.89\right.$ (0.3) 1, mean change 0.29 (95\% CI 0.18 to 0.40$) 1$, FVC 2.70 (0.40) 1 , mean change 0.33 ( 0.23 to 0.43 ) l; both $\mathrm{p}<0.05$ ). The values remained lower than in the controls $(p<0.05)$. Inflammatory markers during acute exacerbations were significantly higher than in the controls: CRP, 48 (19) versus 2 (0.6), mean difference 46 (17 to 75 ) g/l; total white blood cell count, $10.8(0.8)$ versus $5.5(0.2)$, mean difference $5.3(4.7$ to 5.9$) \times 10^{9} / 1$; NEAPC, 4.6 (2.4) versus 0.18 (0.02), mean difference 4.42 (1.8 to 7.1$) \mathrm{mg} / \mathrm{l}$ (all $\mathrm{p}<0.05)$. CRP, white blood cell count and NEAPC concentrations were all reduced in patients following treatment compared with during exacerbations: CRP, 22 (7), mean change $-26(-10$ to -42$) \mathrm{g} / \mathrm{l}$; white blood cell count, $9.3(0.7)$, mean change $-1.5(-1.3$ to -1.7$) \times 10^{9} / 1$; NEAPC, $1.5(0.6)$, mean change $-3.1(-1.3$ to -4.9$) \mathrm{mg} / \mathrm{l}$ (all $\mathrm{p}<0.05)$. The values remained higher than those of the controls $(\mathrm{p}<0.05)$.

AQUEOUS PHASE SCAVENGERS AND MARKERS OF FREE RADICAL DAMAGE

Absolute mean (SE) levels of aqueous phase scavengers and markers of free radical damage in the two groups are summarised in table 2 . During exacerbations patients had a lower plasma vitamin $\mathrm{C}$ concentration than control subjects (36.3 (19.0) versus 55.3 (18.2), mean difference $-19.0(-2.7$ to -35.3$) \mu \mathrm{mol} / 1$, $\mathrm{p}<0.05)$ which did not change following treatment with intravenous antibiotics. Total protein sulphydryls were significantly lower in patients during infection than in controls (299 (59) versus 421 (75), mean difference -122 $(-77$ to -167$) \mu \mathrm{mol} / 1, \mathrm{p}<0.005)$ and increased significantly after treatment to 349 (55) $\mu \mathrm{mol} / 1$ (mean change 50 (95\% CI 32 to 68$) \mu \mathrm{mol} / 1$, $\mathrm{p}<0.01$ ), but continued to remain lower than levels in control subjects, although not statistically significantly so. Lipid standardised MDA was higher during exacerbations than in control subjects (362 (136) versus 169 (24), mean difference 193 (107 to 279 ) $\mathrm{nmol} / \mathrm{mmol}$ cholesterol, $\mathrm{p}<0.05$ ) and remained high following treatment (306 (73) nmol/mmol cholesterol) compared with controls $(\mathrm{p}<0.05)$. MDA levels decreased following treatment (mean difference -56 ( -28 to -84 ) but this change did not reach significance. There was no change between the two observations in patients. Protein carbonyl concentrations during exacerbations were not significantly different from control subjects $(0.58 \quad(0.14)$ versus 0.53 $(0.14) \mu \mathrm{mol} / \mathrm{g}$ protein) but increased after treatment $(0.97(0.37) \mu \mathrm{mol} / \mathrm{g})$ to become significantly higher than during exacerbations (mean change 0.39 (0.11 to 0.67$) \mu \mathrm{mol} / \mathrm{g}$ protein, $\mathrm{p}<0.05)$ and than levels in control subjects (mean difference $0.44 \quad(0.14$ to $0.74) \mu \mathrm{mol} / \mathrm{g}$ protein, $\mathrm{p}<0.005)$. The percentage of PUFAs in red cell membranes of patients was lower during exacerbations than in control subjects (35.0 (8.2) versus 39.4 ( 4.7$)$, mean difference $-4.4(-2.6$ to -6.2$)$ moles percent, $\mathrm{p}<0.01)$. PUFAs did not increase with treatment and remained lower than controls $(\mathrm{p}<0.05)$. 
Table 2 Mean (SE) aqueous phase antioxidants and markers of free radical damage in the plasma of patients with cystic fibrosis during an exacerbation and after antibiotic treatment and in controls

\begin{tabular}{llll}
\hline & \multicolumn{2}{l}{ Patients $(n=12)$} & \\
\cline { 2 - 3 } & Exacerbation & After treatment & $\begin{array}{c}\text { Controls } \\
(n=12)\end{array}$ \\
\hline Ascorbate $(\mu \mathrm{mol} / \mathrm{l})$ & $36.3(19.0)^{\mathrm{a} 1}$ & $43.4(16.7)$ & $55.3(18.2)$ \\
Sulphydryls $(\mu \mathrm{mol} / \mathrm{l})$ & $299(59)^{\mathrm{c} 1}$ & $349(55)^{\mathrm{b} 2}$ & $421(75)$ \\
MDA $(\mathrm{nmol} / \mathrm{mmol} \mathrm{cholesterol})$ & $362(136)^{\mathrm{a} 1}$ & $306(73)^{\mathrm{a} 1}$ & $169(24)$ \\
Protein carbonyls $(\mu \mathrm{mol} / \mathrm{g}$ protein $)$ & $0.58(0.14)$ & $0.97(0.37)^{\mathrm{a} 1 \mathrm{c} 22}$ & $0.53(0.14)$ \\
PUFAs $($ moles percent) & $35.0(8.2)^{\mathrm{b} 1}$ & $36.5(4.9)^{\mathrm{a} 1}$ & $39.4(4.7)$ \\
\hline
\end{tabular}

$\mathrm{MDA}=$ malondialdehyde PUFA = polyunsaturated fatty acids.

${ }_{\mathrm{p}}^{\mathrm{a}}<0.05,{ }^{\mathrm{b}} \mathrm{p}<0.01,{ }^{\mathrm{c}} \mathrm{p}<0.005,{ }^{1}$ versus control, ${ }^{2}$ versus first patient observation.

Table 3 Mean (SE) concentrations of lipid phase antioxidants and total cholesterol in the plasma of patients with cystic fibrosis during an exacerbation and after antibiotic treatment and in controls

\begin{tabular}{llll}
\hline & \multicolumn{2}{l}{ Patients $(n=12)$} & \\
\cline { 2 - 4 } & Exacerbation & After treatment & $\begin{array}{c}\text { Controls } \\
(n=12)\end{array}$ \\
\hline Retinol $(\mathrm{nmol} / \mathrm{mmol}$ cholesterol) & $328(140)^{\mathrm{a} 1}$ & $480(170)^{\mathrm{b} 2}$ & $565(201)$ \\
$\alpha$-carotene $(\mathrm{nmol} / \mathrm{mmol}$ cholesterol) & $5.6(3.6)$ & $6.2(4.3)^{\mathrm{c} 2}$ & $17.1(4.5)$ \\
$\beta$-carotene $(\mathrm{nmol} / \mathrm{mmol}$ cholesterol) & $24.0(16.4)^{\mathrm{d} 1}$ & $31.6(15.8)^{\mathrm{c} 1 \mathrm{c} 2}$ & $76.8(25.6)$ \\
$\alpha$-tocopherol $(\mathrm{nmol} / \mathrm{mmol}$ cholesterol) & $4802(1880)$ & $5641(1845)^{\mathrm{a} 2}$ & $4717(1618)$ \\
$\gamma$-tocopherol $(\mathrm{nmol} / \mathrm{mmol}$ cholesterol) & $326(85)$ & $390(124)$ & $402(104)$ \\
Luteine $(\mathrm{nmol} / \mathrm{mmol}$ cholesterol) & $20.6(8.7)^{\mathrm{d} 1}$ & $24.3(11.2)^{\mathrm{d} 1}$ & $71.0(29.6)$ \\
Lycopene $(\mathrm{nmol} / \mathrm{mmol}$ cholesterol) & $20.4(8.7)^{\mathrm{d} 1}$ & $28.6(25.5)^{\mathrm{d} 1 \mathrm{a} 2}$ & $110.5(31.3)$ \\
Ubiquinol $10(\mathrm{nmol} / \mathrm{mmol}$ cholesterol) & $142(36)$ & $135(35)$ & $146(21)$ \\
Total cholesterol $(\mathrm{mmol} / \mathrm{l})$ & $3.4(0.8)^{\mathrm{d} 1}$ & $3.7(1.2)^{\mathrm{a} 1}$ & $4.9(0.8)$ \\
\hline
\end{tabular}

${ }^{\mathrm{a}} \mathrm{p}<0.05,{ }^{\mathrm{b}} \mathrm{p}<0.01,{ }^{\mathrm{c}} \mathrm{p}<0.005,{ }^{\mathrm{d}} \mathrm{p}<0.001,{ }^{1}$ versus control, ${ }^{2}$ versus first patient observation.

LIPID PHASE SCAVENGERS AND TOTAL

CHOLESTEROI

Absolute mean (SE) values of lipid phase scavengers and total cholesterol in the two groups are summarised in table 3. Compared with controls, during exacerbations patients had a lower lipid adjusted plasma retinol (328 (140) versus 565 (201), mean difference -237 ( -47 to -427) $\mathrm{nmol} / \mathrm{mmol} \quad$ cholesterol, $\mathrm{p}<0.05)$, $\beta$-carotene (24.0 (16.4) versus 76.8 (25.6), mean difference $-52.8(-11.8$ to -93.8$) \mathrm{nmol} /$ mmol cholesterol, $\mathrm{p}<0.001)$, luteine (20.6 (8.7) versus 71.0 (29.6), mean difference -50.4 $(-10.4$ to -90.4$) \mathrm{nmol} / \mathrm{mmol}$ cholesterol, $\mathrm{p}<0.001)$, and lycopene (20.4 (8.7) versus 110.5 (31.3), mean difference -90.1 ( -30.1 to -120.1) $\mathrm{nmol} / \mathrm{mmol}$ cholesterol, $\mathrm{p}<0.001)$. Following treatment the levels of lipid phase scavengers increased as follows: retinol, 480 (170), mean change 152 (47 to 257) nmol/ mmol cholesterol ( $\mathrm{p}<0.01) ; \alpha$-carotene, 6.2 (4.3), mean change $0.6(0.0$ to 1.2$) \mathrm{nmol} /$ mmol cholesterol $(\mathrm{p}<0.005) ; \beta$-carotene, 31.6 (15.8), mean change $7.6(0.0$ to 15.2$) \mathrm{nmol} /$ mmol cholesterol ( $\mathrm{p}<0.005) ; \alpha$-tocopherol, 5641 (1845), mean change 839 (283 to 1405) $\mathrm{nmol} / \mathrm{mmol}$ cholesterol ( $<<0.05)$; and lycopene 28.6 (25.5), mean change 8.2 (0.0 to 16.2) $\mathrm{nmol} / \mathrm{mmol}$ cholesterol $(\mathrm{p}<0.05)$. Following treatment, levels of the lipid phase scavengers remained lower than in controls as follows: $\beta$-carotene, mean difference -45.2 $(-7.7$ to 82.7$) \mathrm{nmol} / \mathrm{mmol}$ cholesterol $(\mathrm{p}<0.005)$; luteine, mean difference -46.7 $(-6.7$ to -86.7$) \mathrm{nmol} / \mathrm{mmol}$ cholesterol $(\mathrm{p}<0.001)$; and lycopene, mean difference -81.9 (0.0 to -163.8$) \mathrm{nmol} / \mathrm{mmol}$ cholesterol $(\mathrm{p}<0.001)$. During exacerbations patients had a lower total cholesterol level than controls (3.4 (0.8) versus $4.9(0.8)$, mean difference 1.5 (0.9 to 2.1$) \mathrm{mmol} / \mathrm{l}, \mathrm{p}<0.001)$ which remained lower than control values following treatment (3.7 (1.2) $\mathrm{mmol} / \mathrm{l}, \mathrm{p}<0.05)$.

\section{Discussion}

Oxygen derived free radicals, or reactive oxygen species (ROS), continuously produced by normal metabolic pathways have the potential to cause extensive functional and structural damage by attacking structural polyunsaturated fatty acids, proteins (particularly enzymes), carbohydrates and DNA. ${ }^{17}$ To cope with this attack the body has evolved a complex antioxidant defence system. Providing that the balance of pro-oxidants and antioxidants is maintained, damage is avoided. The evidence for a major contribution by ROS to the progressive pulmonary damage seen in cystic fibrosis is not conclusive. This chronic damage may be exacerbated during infection. To provide evidence to support a role for chronic free radical activity in cystic fibrosis, and its intensification during acute respiratory exacerbations, we investigated components of the process during respiratory exacerbations and following two weeks of treatment with antibiotics. The reason for examining patients during acute exacerbations first and then following treatment was imposed by logistic considerations and the unpredictability of the onset of an exacerbation.

Free radical activity can be measured by assessing the consequences of free radical damage in the circulation. This imposes limitations on the validity of the data as the process is being examined at one remove from the actual site of damage. It is important to consider this limitation when interpreting results as this systemic evidence of increased oxidative stress cannot be guaranteed to reflect solely those processes occurring in the bronchi. The main lipid target of free radicals in the lungs of patients with cystic fibrosis are the PUFA side chains of the phospholipid component of cellular membranes found in lung epithelial cells. ${ }^{18}$ While these cell membranes are inaccessible, the use of erythrocyte membranes as surrogates to examine free radical attack on membranes may be supported.

Erythrocytes have a number of features which make them suitable for this purpose. They have no nucleus or mitochondria, have a turnover of 120 days, are terminally differentiated, and are readily available. Evidence of free radical damage to cell membranes is reflected by a decreased percentage of PUFAs. The PUFAs of lipoproteins undergo peroxidation resulting in the formation of lipid hydroperoxides and their degradation products such as MDA. ${ }^{19}$ When this compound is measured using a specific HPLC method it is widely accepted as a marker of lipid peroxidation, despite reservations about specificity. Another target for free radical attack is proteins. Oxidative damage to a number of amino acid residues and the peptide backbone of the protein molecule leads to the formation of protein carbonyls. ${ }^{12}$

We have shown evidence of increased inflammation, increased free radical damage, and decreased scavenging capacity in patients 
with cystic fibrosis which was greatest during an acute respiratory exacerbation. As expected, levels of CRP, NEAPC and WCC were all greatly increased in the patients compared with controls, reflecting the consequence of the infection and the defensive response. The generation of free radicals is reflected in the increased levels of MDA. The membranes of circulating red blood cells also showed evidence of increased free radical damage with decreased levels of PUFAs compared with red cell membranes from control subjects. In contrast, evidence of free radical damage to proteins in the form of increased protein carbonyls was not present during an exacerbation. Almost all of the antioxidant scavengers developed to cope with this attack were partially depleted during infection. These antioxidant systems may be grouped into those operating in the aqueous domain (ascorbate and protein thiols), those operating in the lipid domain (carotenoids and ubiquinol), and intracellular antioxidant enzymes.

Ascorbate in the aqueous domain scavenges superoxide and hydroxyl radicals, hydrogen peroxide and hypochlorous acid, as well as recycling $\alpha$-tocopherol at the aqueous lipid interface. Existing data on ascorbate levels in blood of patients with cystic fibrosis is conflicting with reduced, increased, and unchanged levels having been described. ${ }^{20-22}$ In this study we have shown a moderate but significant reduction in ascorbate levels during infection compared with controls. Sulphydryls were also significantly reduced compared with controls. The aqueous free radical, by reacting with a lipid domain scavenger at the aqueous-lipid interface, translates itself into the lipid domain by converting the scavenger into a radical which can initiate lipid peroxidation. ${ }^{15}$ The physiological significance of lipid phase antioxidants is related to their concentrations in membranes. For this reason the plasma concentrations are corrected for total cholesterol to reflect membrane concentrations better. During infection the levels of retinol, $\beta$-carotene, luteine, and lycopene were all severely reduced compared with controls while levels of $\alpha$-carotene and $\gamma$-tocopherol, although lower, did not reach statistical significance. There was no change in ubiquinol levels during or after treatment of infection. This may reflect the ready availability of ubiquinol from endogenous synthesis but gives no information on its rate of consumption. Levels of $\alpha$-tocopherol were not reduced compared with controls. $\alpha$-tocopherol deficiency has been a feature of patients with cystic fibrosis in many, although not all, studies. ${ }^{23}$ Our patients received continuous vitamin $\mathrm{E}$ supplementation, making it impossible to assess basal levels.

Treatment of the infection with antibiotics showed a general improvement in markers for inflammation, oxidative damage, and levels of scavengers. CRP, NEAPC, and WCC all improved. This is to be expected as it has previously been shown that antibiotic treatment reduces lung inflammation in patients with cystic fibrosis ${ }^{24}$ which should result in decreased oxygen radical production. This is confirmed by the reduction in MDA levels compared with pretreatment levels. The percentage of PUFAs on red cell membranes also increased towards the levels found in control subjects. While treatment reduced the degree of lipid peroxidation, it remained raised compared with controls. These findings are consistent with other studies. ${ }^{11}$ Levels of retinol, $\alpha$ - and $\beta$-carotene, and lycopene all increased significantly following treatment while levels of $\gamma$-tocopherol and luteine, although increased, did not reach significance. $\alpha$-tocopherol levels also increased significantly compared with baseline levels following treatment.

A central role has been ascribed to vitamin $\mathrm{E}$ as a protective scavenger in a wide range of free radical mediated diseases. While the initial levels during acute respiratory exacerbation were similar to controls (due to continuous supplementation), this level did increase significantly following treatment. With unchanged supplementation this would support the role of vitamin $\mathrm{E}$ in scavenging. These findings are in agreement with previous studies. We have shown extreme deficiencies of carotenes with $\alpha$ - and $\beta$-carotene and lycopene showing some recovery after treatment. ${ }^{25}$ Paradoxically, levels of protein carbonyls were not significantly increased during acute respiratory exacerbations although they did increase significantly following treatment, indicating oxidative protein damage. This may demonstrate a time delay for free radical mediated protein damage to be reflected in the circulation. Brown and Kelly found no evidence of protein oxidation, whereas in our patients this marker increased two weeks after the start of an acute exacerbation which suggests that basal free radical activity may not induce protein damage. ${ }^{11}$

While treatment did improve indices of inflammation, oxidative stress, and scavenging, almost all remained abnormal, reflecting the chronic inflammation present between periods of acute respiratory exacerbations. The differing degree and rate of change in indices, particularly protein carbonyls, suggests that the change in dynamics for each marker may not be tightly linked. This makes it impossible to assess the situation reliably on one occasion only.

In summary, our results confirm defects in almost all the components of free radical generation, damage, and defence in patients with cystic fibrosis. There is evidence of increased oxidative damage. This is most probably due to the immune hyperresponse to infection compounded by decreased antioxidant cover due to a combination of decreased absorption and increased consumption. These findings support the concept of chronic basal free radical attack which is intensified during periods of acute infection. Antibiotic treatment of the acute infection tends to reduce measures of free radical damage by moderating the infection and hence the immune response. The continual damage is caused by exhausted antioxidant defences being unable to recover in the spaces between exacerbations due to this basal attack. This also highlights the dynamic nature 
of the markers used, showing dependence upon their relation in time to infection. The nature of the results obtained dictates caution in interpretation, however. While the results were analysed as a group, the range of results highlights the differing responses in individuals. As with Brown and Kelly, we found a considerable spread in markers for lipid peroxidation, with some patients showing no change and some showing markedly altered levels. ${ }^{11}$ Some patients had no detectable levels of scavengers and extremely high markers of damage, while in other individuals the levels were relatively normal. The sequence and severity of changes over time in relation to infection are worthy of study, which can only be achieved by a prospective study in which individuals are constantly and regularly monitored. The limitations of using peripheral markers for a highly compartmentalised process must also be stressed. This could be addressed by directly examining the properties of harvested sputum for evidence of free radical activity and also its effect upon cultured small airway epithelial cells in vitro.

There is a consensus that antioxidant vitamin supplementation benefits patients with cystic fibrosis. However, the proposal that an extra aggressive arm of treatment aimed at restoring the oxidant/antioxidant balance be used in addition to conventional treatments, particularly during periods of exacerbation, must be treated with caution. This is due to the fact that most of the scavengers can act as both antioxidants and oxidants depending upon the concentration and the compartment in which they find themselves. This in turn is influenced by the route of delivery. Our results show a wide variation in markers for all aspects of the antioxidant/oxidant balance, therefore such treatment would need to be tailored for each individual. This is compounded by the limitations of methods for assessing the extent of free radical activity. The success of such a treatment will require the successful development of technology to match the dose and route of delivery of active agents to processes taking place in the individual.

This study was supported by the Irish Lung Foundation.

1 Munro JM, Cotran RS. The pathogenesis of atherosclerosis: atherogenesis and inflammation. Lab Invest 1988;58:249 53.

2 Ames BN. Endogenous oxidative DNA damage, ageing and cancer. Free Radic Res Commun 1989;7:121-8. McMurlan MA, Tomkins AM, Garlick PJ. The effect of
starvation on the rate of protein synthesis in the rat liver starvation on the rate of protein synthesis in the

4 Salh B, Webb K, Guyan PM, et al. Aberrant free radical Salh B, Webb K, Guyan PM, et al. Aberrant free radical activity in cystic fibrosis. Clin Chim Acta 1989;181:65-74.
Davis PBO. Pathophysiology of the lung disease in cystic fibrosis. In: Davis PB, ed. Cystic fibrosis. New York: Marcel Dekker, 1993: 193-218.

6 Holsclaw DS. Cystic fibrosis and pulmonary involvement from multiple perspectives. Semin Respir Infect 1993;7:141-

7 Brown RK, Kelly FJ. Role of free radicals in the pathogenesis of cystic fibrosis. Thorax 1994;49:738-42.

8 Feigal RI, Shapiro BL. Mitochondrial calcium uptake and oxygen consumption in cystic fibrosis. Nature 1979;278: oxygen
$276-7$.

9 Winklhofer-Roob BM, Schlegelhaueter SE, Khoschsorur G, et al. Serum neutrophil elastase alpha-1-antiprotease complexes and lipid peroxides decrease during improvement of beta-carotene status in cystic fibrosis. FASEB f 1995;9: 854 .

10 McGrath LT, Douglas AF, McClean E, et al. Oxidative stress and erythrocyte membrane fluidity in patients undergoing regular dialysis. Clin Chim Acta 1995;235:17988.

11 Brown RK, Kelly FJ. Evidence for increased oxidative damage in patients with cystic fibrosis. Pediatr Res 1994;36:48793.

12 Levine RL, Garland D, Oliver CN, et al. The determination of carbonyl content in oxidatively modified proteins. In: Packer L, Glaver AN, eds. Methods in Enzymology, Vol 186. London: Academic Press, 1990: 464-77.

13 Thurnham DI, Smith E, Flora PS. Concurrent liquidchromatographic assay of retinol, $\alpha$-tocopherol, $\beta$-carotene, $\alpha$-carotene, lycopene and $\beta$-cryptoxanthin in plasma with tocopherol acetate as an internal standard. Clin Chem 1988;34:377-81.

14 Inyami $\mathrm{K}$, Yoshiura $\mathrm{M}$, Iwamoto $\mathrm{T}$, et al. Simultaneous determination of uric acid and ascorbic acid in human serum by reversed-phase high-performance liquid chromatography with elctrochemical detection. Anal Biochem 1984;141:2387-43.

15 Stocker R, Bowry VW, Frei B. Ubiquinol-10 protects human low density lipoprotein more efficiently against lipid peroxidation than does $\alpha$-tocopherol. Proc Natl Acad Sci USA 1991;88:1646-50

16 McGrath LT, Elliott RJ. Lipid analysis and fatty acid profiles of individual atherosclerotic plaques. Anal Biochem 1990; 187:273-6.

17 Reilly PM, Schiller HJ, Bulkley GB. Pharmacologic approach to tissue injury mediated by free radicals and other reactive oxygen metabolites. Am f Surg 1991;161: 488-503.

18 Rice-Evans CA, Diplock AT, Symons MCR. Techniques in free radical research. In: Burdon RH, Knippenberg PH, eds. Laboratory techniques in biochemisty

19 Tribble DL, Yee AWT, Jones DP. The pathophysiological significance of lipid peroxidation in oxidative cell injury. Hepatology 1976;7:377-87.

20 Congden PJ, Bruce G, Rothburn MM. Vitamin status in treated patients with cystic fibrosis. Arch Dis Child 1981;56: 708-14.

21 Langley SC, Brown RK, Kelly FJ. Reduced free-radicaltrapping capacity and altered plasma anti-oxidant status in cystic fibrosis. Pediatr Res 1993;33:247-50.

22 Brown RK, Wyatt H, Price JF, et al. Pulmonary dysfunction in cystic fibrosis is associated with oxidative stress. Eur Respir f 1996;9:334-9.

23 Winklhofer-Roob BM. Oxygen free radicals and antioxidants in cystic fibrosis: the concept of an oxidant-
antioxidant imbalance. Acta Paediatr Suppl 1994;395:4957 .

24 Meyer KC, Lewandoski JR, Zimmerman JJ, et al. Human neutrophil and elastase/alpha-1-antiprotease complex in ystic fibrosis. Comparison with interstitial lung disease and evaluation of the effect of intravenously administered antibiotic therapy. Am Rev Respir Dis 1991;144:580-5.

25 Homnick DN, Cox JH, DeLoof MJ, et al. Carotenoid levels in normal children and in children with cystic fibrosis. $f$ Pediatr 1993;122:703-7. 